\title{
GESTÃO ESTRATÉGICA DE PESSOAS PARA A INOVAÇÃO: O CASO DA FRIMESA COOPERATIVA CENTRAL
}

\author{
INNOVATION-ORIENTED STRATEGIC MANAGEMENT OF PEOPLE: \\ FRIMESA COOPERATIVA CENTRAL CASE
}

Recebido - 14.01.11

Aceito - 12.04.2011

\author{
Sonia Regina Hierro Parolin ${ }^{1}$ \\ e Lindolfo Galvão de Albuquerque ${ }^{2}$
}

\section{Resumo}

Visando contribuir com a integração das estratégias de gestão de pessoas com inovação, a pesquisa visou identificar relações entre as características organizacionais e o espaço para a criatividade, em uma organização inovativa. As variáveis de características organizacionais abrangeram: estrutura organizacional, filosofia e valores, políticas e sistemas de recursos humanos; as de espaço para a criatividade: encorajamento à criatividade, ambiente da tarefa, recursos e impedimentos organizacionais. O estudo qualitativo exploratóriodescritivo foi realizado em grande empresa inovadora do segmento de laticínios. Foram realizadas entrevistas com gestores de recursos humanos e de tecnologia e aplicação de questionários a 68 funcionários técnicos e administrativos. Os principais resultados demonstram a integração de estratégias de gestão de pessoas e inovação e apontam que o espaço para a criatividade é permeado por práticas de valorização das pessoas e de seus resultados na organização. As práticas de gestão de pessoas mais evidenciadas relacionam-se aos feedbacks construtivos na avaliação de desempenho.

Palavras-chave: Criatividade. Gestão de pessoas. Gestão da inovação. Estratégias. Organização inovativa.

\footnotetext{
1 Doutora em Administração pela Faculdade de Economia, Administração e Contabilidade da Universidade de São Paulo (FEA-USP), gerente de inovação do Serviço Nacional de Aprendizagem Industrial do Paraná (SENAI PR), membro do grupo de pesquisa de gestão estratégica de pessoas FEA/USP, professora em cursos de pós-graduação. Brasil. E-mail: sonia.parolin@pr.senai.br

2 Doutor em Administração e livre-docente pela Faculdade de Economia, Administração e Contabilidade da Universidade de São Paulo (FEA-USP), onde é professor titular. Possui cursos no INSEAD/França, na Vanderbilt University e na Northwestern University/EUA. Brasil. E-mail: Igdalbuq@usp.br
} 


\begin{abstract}
Aiming at contributing to the integration of the strategies for management of people with innovation, the research focused on identifying relationship between organizational characteristics and space for creativity in an innovative organization. The variables of the organizational characteristics have involved: organizational structure, philosophy and values, and policies and human resources systems; the variables of space for creativity have involved: encouragement for creativity, assignment environment, organizational resources and impediments. Interviews with HR and technology managers have been held, as well as the application of a questionnaire to 68 technical and administrative collaborators. The main results demonstrates the policies and practices that promote the integration of the strategies of management of people with innovation, and pointed that the space for creativity is permeated by the effective people and groups valorization and the results they produce within the organization. The main results demonstrates the policies and practices that promote constructives feedbacks in performance evaluation.
\end{abstract}

organization.

Keywords: Creativity. Human research management. Innovation management. Strategies. Innovative

\title{
1 INTRODUÇÃO
}

Na década passada, inúmeros estudos já apontavam para a emergência de mudanças no milênio recém-iniciado, cuja primeira década apresenta a inovação (existente ou potencial), alinhada à estratégia organizacional, como uma das prerrogativas para ganhos com eficiência e competitividade global (SWAN; SCARBROUGH; HISLPO,1999). Algumas condições se evidenciam para o alinhamento entre inovação e estratégia organizacional, sendo que, entre elas, têm-se os investimentos para alavancar a tecnologia e as competências internas e, especialmente, o desafio de conduzir a inovação ao todo da organização (JONASH, 2001).

Essa condução ao todo da organização passa pelas condições intraorganizacionais relacionadas à cultura, ao clima organizacional e à gestão (SLUIS, 2004), pelas iniciativas dos colaboradores que introduzem novos processos, produtos, mercados ou combinação entre eles na empresa (AMO; KOLVAREID, 2005), de tal maneira que, para Pohlmann, Gebhardt e Etzkowitz (2005) a ação preliminar de empresas inovativas são os recursos humanos que devem interagir e agir com coerência.

Alguns estudos sobre as pessoas como elementos diferenciais para a obtenção da inovação discutem a integração nas estratégias de gestão de recursos humanos (SHRM - Strategic Human Resource Management). Propõem integração entre políticas e práticas de gestão de pessoas, considerando modelos multidimensionais que evidenciam algumas características organizacionais inerentes ao contexto e que contribuem para resultados em inovação, incluindo criatividade como input e output ao processo (FERRIS et al., 1999; ALBUQUERQUE, 1999; 2002; DUTRA, 2002; LAURSEN; FOSS, 2003; ALIAGA, 2005; LEEDE; LOOISE, 2005; MARTINALCAZAR; ROMERO-FERNANDEZ; SANCHEZ-GARDEY, 2005).

Por outro lado, estudos sobre inovação tratam da relevância do estímulo à criatividade dos colaboradores para a obtenção da inovação e abordam os dificultadores e os facilitadores do processo no ambiente organizacional, contudo, sem um referencial alinhado à estratégia de gestão de pessoas (AMABILE; GRYKIEWICZ, 1989; EKVALL, 1996; AMABILE et al., 1996; ISAKEN et al., 2000-2001; KWASNIESWSKA; NECKA, 2004). Os referidos estudos, porém, não ampliam as discussões para a construção de um modelo de gestão que permita às organizações determinarem o nível de contribuição desses indicadores para o alcance do seu intento estratégico. 
Falta ao construto sobre criatividade nas organizações um referencial de gestão alinhado à estratégia de gestão de pessoas.

Observa-se que a combinação dos construtos entre gestão de pessoas e inovação pode ser mais explorada, pois aponta para a necessidade de uma conexão entre elas, alinhada aos objetivos organizacionais. Diante dessas discussões, este artigo apresenta um estudo de caso que visou identificar a relação entre as características organizacionais (estrutura; filosofia e valores; e políticas e sistemas de recursos humanos) e o espaço para a criatividade em organizações inovativas, um enfoque, até então, pouco explorado nas pesquisas brasileiras. O estudo de caso foi realizado na Frimesa Cooperativa Central, empresa de grande porte na área de alimentos, situada no oeste paranaense e atuante nos setores cárneo e lácteo.

Diante disso, este artigo está estruturado da seguinte maneira: após a introdução, discute-se o alinhamento estratégico entre a gestão de pessoas, evidenciando aquelas que ampliam as possibilidades de se obter um ambiente que favoreça a criatividade para a inovação; na sequência, apresenta-se as abordagens sociointeracionistas sobre criatividade, com destaque para as abordagens de Amabile et al. (1996) e Amabile (1998), que embasaram a construção das variáveis de espaço para a criatividade; o terceiro item apresenta os procedimentos metodológicos adotados para a pesquisa, seguido da apresentação e da análise dos resultados do estudo do caso. O relato é estruturado a partir do breve histórico da empresa com atividades inovativas e apresenta os resultados das variáveis pesquisadas, seguido das considerações finais sobre o estudo.

\section{REFERENCIAL TEÓRICO}

\subsection{Alinhamento estratégico entre gestão de pessoas e inovação}

Estudos sobre as pessoas como elementos diferenciais para a obtenção da inovação discutem as políticas e as práticas de gestão de pessoas, tanto no nível do modelo conceitual quanto da viabilidade de sua aplicação em diferentes contextos culturais e organizacionais. Discutem, ainda, a integração das estratégias de gestão de recursos humanos (SHRM - Strategic Human Resource Management) - políticas e práticas -, considerando os modelos multidimensionais que evidenciam algumas características organizacionais inerentes ao contexto (ALIAGA, 2005: ALBUQUERQUE, 1999; 2002; DUTRA, 2002), que contribuem para resultados em inovação (FERRIS et al., 1999; LAURSEN; FOSS, 2003), incluindo criatividade como input e output ao processo (LEEDE; LOOISE, 2005; MARTIN-ALCAZAR; ROMEROFERNANDEZ; SANCHEZ-GARDEY, 2005).

Aliaga (2005) apresenta um modelo integrativo das inovações organizacionais com inovações em gestão e desenvolvimento de pessoas, em que o foco se dá pelas características organizacionais de sustentação dessa integração, tais como o clima e a estrutura organizacional. Leede e Looise (2005) abordam a integração de gestão de recursos humanos com inovação pela estratégia organizacional, e o impacto dessa integração é medido pelo aumento crescente da criatividade, do comprometimento e das competências dos colaboradores. Martin-Alcazar, Romero-Fernandez e Sanchez-Gardey (2005) consideram os efeitos no nível organizacional (clima, cultura, estrutura, inovação, tecnologia etc.), social (legislação, políticas, governo etc.) e individual (performance, satisfação, comprometimento e aprendizagem). 
Albuquerque $(1999,2002)$, comparando a estratégia de controle (administração tradicional de recursos humanos) com a estratégia do comprometimento das pessoas com os objetivos organizacionais (gestão estratégica de pessoas), identificou características organizacionais substancialmente diferentes entre elas. Para uma gestão estratégica de pessoas, o autor aponta características organizacionais que abrangem estrutura organizacional (organização e realização do trabalho e sistema de controle), filosofia e valores (valores essenciais e comunicação interna) e políticas e sistemas de recursos humanos (contratação, treinamento, carreira, regime salarial e de incentivos). Complementarmente, Dutra (2002) sugere condições organizacionais que viabilizem o direcionamento do potencial das pessoas para a estratégia organizacional, voltada para uma organização inovativa.

São contribuições relevantes e, a partir da convergência entre elas, acrescidas das contribuições de demais autores, compôs-se o constructo sobre as características organizacionais, definidas a seguir, que evidenciam as estratégias de gestão de pessoas que ampliam as possibilidades de se obter um ambiente que favoreça a criatividade para a inovação.

a) estrutura organizacional: sendo que a estratégia determina a estrutura, por conseguinte, também determina os níveis de formalização (níveis hierárquicos), de autoridade (centralização/ descentralização), de margem de controle (abrangência e sistemas de normas, regras e procedimentos) e o grau de padronização dos trabalhos (alta/baixa especialização/ formalização do trabalho e sobre o que, como e quando será executado). A forma matricial de organização do trabalho viabiliza a realização de atividades integradas, especialmente quando se refere à inovação (VASCONCELLOS; HEMSLEY, 2003; LAURSEN; FOSS, 2003; ROBBINS, 2005; MARTINALCAZAR; ROMERO-FERNANDEZ; SANCHEZ-GARDEY, 2005);

b) filosofia e valores organizacionais: compreendidos como a ideologia essencial, ou seja, valores essenciais intrínsecos à organização e ao seu propósito essencial (COLLINS; PORRAS, 1996, in ULRICH, 2000). A comunicação exerce importante função como transmissora e mantenedora da filosofia e dos valores organizacionais, com o objetivo de sua internalização pelos colaboradores (DUTRA, 2002; ROBBINS, 2005), e também está intimamente ligada ao funcionamento dos grupos de trabalho e à participação. A comunicação ocorre de maneira horizontal e diagonal nas formas organizacionais (nas estruturas), abrange mensagens e símbolos, verbais e não-verbais, trocas informais de dados e outros processos que possam favorecer os insigths e as múltiplas percepções e concatenações, por toda exposição a que as pessoas ficam sujeitas nessas situações (ROBBINS, 2005; VASCONCELLOS; HEMSLEY, 2003);

c) políticas e sistemas de recursos humanos: os processos de recrutamento, seleção e contratação voltam-se ao desenvolvimento do potencial dos candidatos em níveis iniciais de carreira, enquanto o recrutamento interno se dirige para a valorização dos níveis mais avançados (ALBUQUERQUE, 1999; VASCONCELLOS; HEMSLEY, 2003; MARTIN-ALCAZAR; ROMEROFERNANDEZ; SANCHEZ-GARDEY, 2005). O treinamento está mais direcionado para o desenvolvimento de competências que ampliem a capacidade da pessoa de agregar valor à organização para desempenho de funções futuras (processos de aprendizagem individual, coletiva e organizacional) e as necessidades decorrentes da introdução de inovações e de mudanças organizacionais (ALBUQUERQUE, 1999; 2002; DUTRA, 2002; LAURSEN; FOSS, 2003). A gestão de carreira deixa de ser responsabilidade exclusiva da organização e passa a ser também do indivíduo; à organização, cabe o papel de suporte, de estímulo e de oferta das condições (FERRIS et al., 1999; DUTRA, 2002). Na visão da gestão estratégica de pessoas, as promoções deverão ser baseadas em background individual e desempenho, sustentadas por um sistema de carreiras paralelas, que permite o acesso aos maiores níveis de remuneração (DUTRA, 1996; ALBUQUERQUE, 1999; VASCONCELLOS; HEMSLEY, 2003; LAURSEN; FOSS, 2003; LEEDE; 
LOOISE, 2005; ALIAGA, 2005). A avaliação de desempenho é destacada como ferramenta de retroalimentação e de sustentação dos sistemas de recursos humanos (aspecto social), com critérios claros e definidos e, fundamentalmente, deve facilitar a realização de feedbacks individuais e coletivos pelos gestores (FERRIS et al., 1999; ROBBINS, 2005; DUTRA, 2002). As políticas de remuneração devem focar a posição da carreira e o desempenho como base da equidade interna, com suficiente flexibilidade para remunerar o trabalho inteligente e o desempenho excepcional de forma variável e com benefícios que reconheçam a contribuição (DUTRA, 2002; HIPÓLITO, 2001). Por último, aborda-se a questão dos incentivos, usualmente configurados em sistemas de premiações, quando destinados ao estímulo para a criatividade, preferencialmente direcionados à base grupal (ALBUQUERQUE, 1999).

\subsection{Abordagens sociointeracionistas da criatividade e sua rela- ção com a inovação}

Uma linha de pesquisa sobre a criatividade evidenciada é a que investiga as características de clima de trabalho em ambientes considerados criativos (EKVALL, 1996; ISAKEN et al., 2000-2001; KWASNIESWSKA; NECKA, 2004).

São os estudos de Amabile et al. (1996) e Amabile (1998), desenvolvidos por meio de pesquisas sobre ambientes organizacionais e seus efeitos na criatividade pessoal, que mais vêm influenciando as pesquisas sobre criatividade em nível mundial. Os autores citados analisaram os aspectos socioambientais relacionados à influência dos fatores do ambiente de trabalho sobre a motivação intrínseca do indivíduo, para um modelo de inovação. Desenvolveram o instrumento Work Environment Inventory (WEI), com o objetivo de identificar a presença ou a ausência de estímulos e obstáculos à criatividade no ambiente organizacional. Dessa forma, na medida em que as pessoas possam ser consideradas parceiras e o seu trabalho esteja voltado à inovação, apresentam-se novos estímulos, desafios, autonomia para pensar e decidir (empowerment), entre outros. São implicações que compõem algumas das relações investigadas nesta pesquisa.

Resumidamente, as categorias propostas por Amabile et al. (1996), acrescidas das contribuições de demais autores, compuseram as variáveis de espaço para a criatividade em organizações inovativas adotadas neste estudo, definidas a seguir.

a) encorajamento para a criatividade: fenômeno concebido como receptividade e incentivo da organização, dos gestores e do grupo de trabalho na busca de soluções inovadoras e de manifestação das ideias, com estímulo ao comportamento espontâneo e à continuidade do estudo das mesmas, além da "tolerância ao erro" proveniente do exercício criativo.

b) ambiente de tarefa: compreendido pela autonomia e pela liberdade de decisão e de ação atribuídas ao indivíduo ou ao grupo, em consonância com a filosofia, os valores e os objetivos organizacionais. Considera, ainda, o equilíbrio entre a carga de trabalho e destinação de tempo para a realização das tarefas, a fim de cumprir os prazos com qualidade, além da capacidade de lidar com mudanças organizacionais.

c) recursos: elementos concebidos, como a disponibilidade de equipamentos e materiais diversos; as condições do ambiente físico para o trabalho; os recursos financeiros e tecnológicos disponíveis para a execução das atividades; a destinação de tempo adequado para a experimentação de ideias e projetos inovadores.

d) impedimentos organizacionais: são as influências sociais, políticas e administrativas, como pressões internas e externas relacionadas às mudanças organizacionais que inibem a 
participação e o engajamento dos colaboradores ou que comprometem as relações de confiança recíprocas.

\subsection{Características de uma organização inovativa}

O presente artigo não se propõe a discutir conceitos sobre a inovação em si, mas intenciona abordar as atividades inovativas que dão suporte ao desenvolvimento das inovações, tanto as tecnológicas (de produto ou processo) quanto as de gestão ou de negócios. Para tanto, baseou-se na classificação do Manual de Oslo (2004), das Notas Técnicas da PINTEC/Pesquisa de Inovação Tecnológica (2008) e em Sbragia et al. (2006, p. 49-50):

Pesquisa e Desenvolvimento (P\&D): entendida como o trabalho criativo desenvolvido em uma base sistemática a fim de aumentar o estoque de conhecimento existente; aquisição de tecnologia intangível: aquisição de tecnologia na forma de patentes, licenças, know-how e serviços de conteúdo tecnológico em geral; aquisição de tecnologia tangível: aquisição de máquinas e equipamentos de cunho tecnológico conectados com as inovações de produto e processo introduzidas pela empresa; início da produção: compreende as modificações (retrabalho) de produto e processo, treinamento de pessoal nas novas técnicas e lote experimental; marketing de novos produtos: atividades em conexão com o lançamento do novo produto a diferentes mercados, comercialização pioneira; aquisição de software: compreende a aquisição de software (de desenho, engenharia, de processamento e transmissão de dados, voz, gráficos, vídeos, para automatização de processos, etc.), especificamente comprados para a implementação de produtos ou processos novos ou tecnologicamente aperfeiçoados. Não inclui aqueles registrados em atividades internas em P\&D; design: atividades relativas à definição de procedimentos, especificações técnicas e aspectos operacionais necessários à produção do novo produto ou implementação do novo processo. O design artístico também é considerado uma atividade inovativa quando diretamente relacionado ao novo produto ou processo (ou seja, design meramente estético não é considerado atividade inovativa); engenharia industrial: aquisição ou mudança nos equipamentos, ferramentas, procedimentos de controle de qualidade, métodos e padrões visando à manufatura do novo produto ou aplicação do novo processo.

Para fins deste artigo, compreende-se por organização inovativa aquela que reúne um conjunto de políticas e práticas de gestão de pessoas voltadas à consecução da estratégia organizacional, centrada na inovação (inclusive atividades inovativas), que abrange os processos de gestão em todas as áreas da organização e não somente as relacionadas à área de Pesquisa e Desenvolvimento, podendo apresentar inovações em produtos, em processos, em marketing, em gestão e/ou em negócios, e que está voltada ao desenvolvimento social. Como parâmetros para se considerar uma organização inovativa, considera-se, ainda, que a empresa deve apresentar plataformas de estímulo à criatividade para inovação, histórico com inovações, patentes e com as atividades inovativas, incluindo inovação em gestão ou negócios (SIMANTOB; LIPPI, 2003). 


\section{PROCEDIMENTO METODOLÓGICO}

O método norteador da pesquisa caracterizou-se por exploratório-descritivo, sob abordagem quali-quantitativa baseada em estudo de caso com corte transversal. Não se pretendeu medir o grau de inovação das empresas. Buscou-se explorar e descrever as evidências das características organizacionais que influenciam o espaço para a criatividade na organização, respeitando-se seu contexto, seu histórico e suas especificidades, com a finalidade de encontrar regularidades, padrões, explicações ou configurações (ROESCH, 1999).

Para verificar a relação entre as variáveis independentes (características organizacionais) e dependentes (espaço para a criatividade), procedeu-se ao levantamento das características organizacionais na empresa e à verificação de como as variáveis de espaço para a criatividade nela se manifestam. Para a identificação da organização inovativa, adotaram-se critérios do histórico com inovação, atividades inovativas, prêmios com inovação tecnológica e setores inovadores, segundo Pesquisa de Inovação Tecnológica/PINTEC, promovida pelo IBCE (2003, 2008), além da acessibilidade por parte dos pesquisadores. A empresa estudada foi a Frimesa Cooperativa Central, de grande porte, pertencente ao setor de fabricação de laticínios, de baixa densidade tecnológica, descrita no item 4.1 adiante.

O instrumento de coleta de dados quantitativos foi composto de 66 itens, além dos itens referentes aos dados biográficos e funcionais. Foram utilizadas questões provenientes dos instrumentos já testados pelos autores referendados na pesquisa, com escala Likert de seis pontos (discordo/concordo) e aplicados aos colaboradores das áreas técnicas e administrativas. O propósito de atingir os colaboradores somente dessas áreas deu-se em função de que eles são os profissionais mais participantes das atividades inovativas e, portanto, mais sensíveis às condições que caracterizam o ambiente encorajador à criatividade.

Foram realizadas entrevistas com gestores de Recursos Humanos e de Tecnologia e foi aplicado questionário a 68 funcionários das áreas técnica e administrativa (na sede, localizada na cidade de Medianeira, e na unidade fabril, em Curitiba), o que significou uma taxa de retorno de $64 \%$. A amostra foi composta por $55 \%$ de mulheres, $56 \%$ na área administrativa, $53 \%$ com idade inferior a 30 anos, 58\% com nível superior e 51\% com mais de cinco anos atuando na empresa. O tratamento dos dados quantitativos foi realizado pela estatística básica (média, desvio-padrão e percentual de concordância). Os dados quali-quantitativos (primários e secundários) foram analisados e apresentados conforme as variáveis de pesquisa: i) características organizacionais: estrutura organizacional, filosofia e valores e políticas e sistemas de recursos humanos; ii) espaço para a criatividade: encorajamento para a criatividade, ambiente da tarefa, recursos e impedimentos organizacionais.

\section{RESULTADOS E ANÁLISE}

\subsection{A empresa Frimesa Cooperativa Central}

A Frimesa é uma central de cinco cooperativas situadas na região oeste do Paraná, denominadas filiadas, com seu centro administrativo situado na cidade de Medianeira, oeste do estado. Conta com dez unidades fabris distribuídas pelo Paraná, Mato Grosso do Sul e por Santa 
Catarina e seis filiais de vendas no Paraná, Rio de Janeiro e em São Paulo, e vários distribuidores e representantes nas principais capitais brasileiras.

A cooperativa iniciou suas atividades agroindustriais em 1979 e, com a aquisição do Frigorífico Medianeira S/A, passou a operar com a marca Frimesa. Seu propósito era unir a força do cooperativismo local, integrar as comunidades e fazer com que os produtores continuassem no campo, ampliando a produção industrial da região. No primeiro abate, em 1980, foram 70 suínos; em 2008, foram 160 mil toneladas. Em 1990, inaugurou-se a maior fábrica de queijos finos da América Latina, no estado do Paraná, lançando a marca Reggio.

A empresa atua nos setores de carne e de leite. A unificação dos produtos em marca única deu-se em 1998, com o objetivo de aprimorar e fortificar a comunicação com o consumidor. A empresa ainda possui marcas mistas (Friminho e Reggio) e uma marca independente e tradicional (Rei do Oeste), voltada para o consumidor do oeste paranaense. Seus principais concorrentes no território nacional são: na área de carnes, Sadia e Perdigão; na área de leite, Parmalat e Nestlé. Já obteve vários prêmios, com destaque para o Prêmio Marketing/OCB, em 2005, quando conquistou o 1. lugar, com o projeto "Leite Condensado".

Um dos marcos na sua história foi a superação da crise nas exportações de carnes, em 2006, causada pela febre aftosa que atingiu o gado. O seu principal mercado de suínos era formado pela Rússia, com 30\% do volume de exportação. A superação ocorreu com a adoção da estratégia de produção de industrializados de forma mais intensa para o mercado interno e a redução de custos com despesas internas. A crise foi relatada como "uma marca" que deixou um aprendizado lentamente absorvido pelos colaboradores.

Atualmente, a Frimesa conta com mais de 2.900 colaboradores diretos, sendo $1.900 \mathrm{em}$ Medianeira, 274 em Curitiba e os demais distribuídos nas outras filiais. Em média, são 25.000 pessoas ligadas economicamente à empresa.

Sua política ambiental prevê o tratamento dos efluentes gerados (líquidos, sólidos e gasosos) e mantém 517 hectares de reflorestamento nas áreas próximas às unidades fabris. Em Medianeira, PR, a empresa criou uma reserva ecológica com 70 hectares.

\subsection{Breve histórico da organização com inovações}

A Frimesa pertence ao setor de fabricação de produtos alimentícios, considerado setor de baixa densidade tecnológica (FURTADO; CARVALHO, 2005), mas um dos que mais promoveu inovações, segundo os dados da PINTEC 2003 e 2005. A inovação em produtos e processos constitui uma constante na empresa; contudo, o tema "inovação" somente ganhou posicionamento estratégico na organização em 2006, por causa do movimento do macroambiente em torno das condições de investimentos nesse campo, conforme já comentado. Com a estratégia de cooperativas, a organização solidificou-se no mercado nacional após adotar a marca "Frimesa" como a principal marca para seus produtos. Ao longo de sua existência, tem lançado novos produtos em duas áreas alimentícias: carne e leite. No entanto, a organização não possui registro de patentes, informações confirmadas pelo Instituto Nacional de Propriedade Industrial (INPI).

Nas diretrizes estratégicas da empresa, entre os doze itens previstos, destacam-se dois: (i) a agregação de valor às matérias-primas pelo desenvolvimento de novos produtos e pela inovação tecnológica; (ii) o treinamento dos colaboradores para a gestão da qualidade, inovação e auto-realização. 


\section{Inovações implementadas}

As inovações introduzidas na empresa, decorrentes de processos inovadores, são contínuas. Foi instalado um túnel de choque térmico automatizado para carcaça suína após o abate, o que reduziu de 18 horas para 2 horas o tempo de liberação antecipada da carcaça para desossa. Foram montados: a) um sistema automatizado de corte de carcaças com indicador a laser dos pontos de cortes e com posicionador joystick para maior agilidade, precisão nos cortes, velocidade e sensível redução de risco de acidentes; b) um sistema automatizado para transporte de embalagens via trilho transportador de caixas plásticas; c) um transporte automatizado dos recortes para silos em salas climatizadas; d) um sistema de túnel de congelamento automatizado de horizontal para elevador vertical com bandejas. Essas inovações foram realizadas por meio de aquisição de tecnologia tangível e intangível na forma de equipamentos e de serviços de conteúdo tecnológico.

As inovações efetivadas nos produtos seguem tendências e oportunidades identificadas no mercado, com tecnologias mais avançadas em genética e em sanidade do gado. Para exemplificar, a empresa desenvolve produtos inovadores, como o salame suíno com gosto de limão, inexistente no mercado até a época do seu lançamento.

\subsection{Atividades inovativas desenvolvidas pela organização}

A pesquisa e o desenvolvimento de novos produtos são realizados por dois comitês multifuncionais: da carne e do leite. Ambos estão localizados em Medianeira e contam com a parceria da Universidade Tecnológica Federal do Paraná/UTFPR. Os comitês são compostos por profissionais técnicos de várias áreas da empresa e de representantes da diretoria, com intensa contribuição da área de marketing, que organiza briefings contendo informações provenientes do sistema de atendimento ao consumidor e de vigilância tecnológica.

Nas entrevistas com alguns colaboradores do Comitê de Carnes, relatou-se que o grupo foi composto há dois anos. Atua com reuniões mensais e adota metodologia que inclui etapas de brainstorming, avaliação da viabilidade técnica e comercial, seleção da ideia e desenvolvimento, lançamento e acompanhamento do produto no mercado. A meta do comitê é lançar 60 novos produtos, entre eles os que intensifiquem o consumo da carne de porco no país, "com readequação do processo produtivo, se necessário", conforme afirmação de um dos entrevistados.

Na planta das instalações, na cidade de Medianeira, PR, foram executadas a ampliação dos espaços e a revisão do layout, obtendo redução do tempo do transporte interno dos produtos na fase de elaboração e maior fluxo na recepção e estocagem. A instalação de sistemas inovadores no processo produtivo aprimorou a qualidade dos produtos, principalmente no congelamento, com redução das devoluções e diminuição dos riscos de contaminação.

A Frimesa utiliza laboratórios próprios (2 laboratórios na unidade de Medianeira e 1 na unidade de Curitiba) e equipes treinadas em sistemas de controle, que permitem rastreabilidade de toda a cadeia produtiva, da origem até a entrega do produto no mercado. Possui certificação em ISO 9001:2000 pelo Bureau Veritas Certification (BVQI) utilizando tecnologias limpas para a redução da agressão ao meio ambiente. Na fábrica de Medianeira, à época da coleta dos dados, estava em construção uma nova área fabril, com ampliação das estruturas laboratoriais físicas e tecnológicas. Com essa ampliação, a capacidade de abate será aumentada, de 1.500 para 4.500 cabeças/dia e a industrialização passará de 4.0008 .000 ton./mês. 
A área de marketing da empresa atua intensivamente na organização de informações do mercado, para fomentar, internamente, a geração de ideias de novos produtos, sendo que os investimentos mais expressivos são direcionados à marca institucional do leite condensado. A empresa investe na aquisição de tecnologias de ponta, em nível mundial e de forma sistemáti$\mathrm{ca}$, para o desenvolvimento de novos produtos e para o incremento dos processos inovadores, tanto na forma de conhecimento com profissionais especialmente contratados para o repasse de know-how, como na aquisição de equipamentos.

\subsection{Apresentação das variáveis de características organizacionais}

\subsubsection{Estrutura organizacional}

Essa empresa segue o modelo tradicional de hierarquização, ressaltando-se a diferenciação por ser uma cooperativa com sistema de gestão por governança (VASCONCELLOS; HEMSLEY, 2003). Em seu organograma, a área de Recursos Humanos está diretamente subordinada à Diretoria Executiva, e a área de Tecnologia está inserida na área industrial de Carne e Leite.

Além dos mecanismos formais de comunicação (jornais internos, revistas e intranet), a comunicação interna é incentivada por comitês que incluem gestores de todas as áreas, com o objetivo de ouvir as ideias e sugestões dos demais colaboradores, para apresentá-las nas reuniões mensais com a área de Recursos Humanos. A metodologia adota a "escuta", que tem função de "elo" entre os gestores e os colaboradores e tem como premissa cultivar a confiabilidade mútua.

Muitas normas internas, que não dependem de auditorias, são revisadas nesses comitês. Há flexibilidade, quando se torna evidente para a organização que as normas não atendem mais à dinâmica do processo produtivo. Geralmente, as flexibilizações ocorrem nas normas e nos procedimentos administrativos (área de gestão), que se desdobram em normas de conduta nas diversas áreas. As normas referentes ao Sistema de Qualidade e às demais certificações são comunicadas como procedimentos operacionais que devem ser seguidos sem nenhuma alteração.

Cabe ressaltar que a localização da unidade de Medianeira é muito próxima à fronteira com o Paraguai, e o trabalho informal é muito intenso na região, que dispõe de poucas grandes empresas em condições de oferecer estabilidade e progressão na carreira. Nos relatos dos entrevistados, os comentários acerca desse assunto foram recorrentes. Por outro lado, o hábito da informalidade torna as pessoas mais independentes, e elas não se submetem facilmente às regras que não consideram exequíveis.

A percepção dos respondentes sobre as variáveis de estrutura organizacional é apresentada na tabela 1. 
Tabela 1 - Variáveis de estrutura organizacional

\begin{tabular}{llccc}
\hline Dimensões & Itens & Média & DP & \% Conc. \\
\hline Sistema de comando e & - normas e regras rígidas & 3,43 & 1,201 & $49,20 \%$ \\
Controle & & & \\
\hline Realização do trabalho/ & - não-participação nas decisões & 4,21 & 1,220 & $68,30 \%$ \\
participação & - decisões tomadas em grupo & 3,33 & 1,298 & $46,90 \%$ \\
& - chefes definem & 4,02 & 1,279 & $75,00 \%$ \\
\hline Níveis hierárquicos/novas & - muitos níveis hierárquicos. & 4,19 & 1,153 & $70,40 \%$ \\
ideias & - ideia nova requer aprovação & 4,46 & 1,133 & $77,70 \%$ \\
& - vários em níveis hierárquicos & & & \\
\hline
\end{tabular}

Fonte: elaborada pelos autores.

i) escala de seis pontos, sendo: 1 = discordo totalmente; 6 = concordo totalmente;

ii) $\%$ concordo $=$ somatória de 6 (concordo totalmente) +5 (concordo muito) +4 (concordo pouco);

iii) $\mathrm{DP}=$ desvio-padrão.

Os resultados demonstram o impacto dos níveis hierárquicos para a aprovação de uma nova ideia e a participação dos colaboradores nas decisões da empresa relativamente baixa, mas temperada pela participação das discussões sobre as decisões a serem tomadas, conforme relatos sobre as discussões em grupo. A flexibilização de normas e regras também ficou evidenciada nos resultados acima. Depreende-se que, apesar de as discussões serem incentivadas, as decisões para a aprovação das novas ideias tendem a ser centralizadas.

Apesar de utilizar-se de estruturas mistas calcadas em uma estrutura de governança cooperativada, apresenta-se com níveis de hierarquização que exercem certa inibição à realização de ideias portadoras de inovação (VASCONCELLOS; HEMSLEY, 2003; ROBBINS, 2005). Algumas práticas podem ser destacadas como neutralizadoras da hierarquização na empresa. Uma delas é a constante prática do diálogo nos comitês, oferecendo ampla oportunidade de participação nas discussões em grupo sobre as decisões a serem tomadas na empresa. Essa prática guarda certas reservas quando se trata da participação na tomada de decisões, restringindo a amplitude das possibilidades da prática do empowerment na organização (ALBUQUERQUE, 1999; 2002). O "não-engessamento" das normas e regras e o hábito de questioná-las quando não atendem às necessidades cotidianas aumentam a "oxigenação" e a diversidade das ideias e reforçam que criticidade não é sinônimo de antagonismo ou rebeldia, alguns dos mitos do comportamento criativo. Destaca-se, igualmente, que a flexibilização de normas e regras, acrescida do clima de reciprocidade entre gestores e colaboradores, representa elementos que contribuem para a sedimentação do espaço para a criatividade na organização (CHANG JR., 2001; LAURSEN; FOSS, 2003; PAROLIN; ALBUQUERQUE, 2010).

\subsubsection{Filosofia e valores}

Os valores da Frimesa estão expressos em seu plano estratégico, no qual é concebida como uma empresa de pessoas para satisfazer pessoas e tem como objetivos globais: crescimento, qualidade de gestão, gestão humana, gestão ambiental e recursos financeiros. Adota como missão, que na realidade é seu propósito essencial, conquistar o consumidor oferecendo soluções em alimentação. Sua visão é ser uma das melhores empresas no mercado de alimentos, satisfazendo as expectativas dos clientes, dos colaboradores e da sociedade, proporcionan- 
do rentabilidade aos acionistas, através de uma gestão comprometida com a qualidade. Suas crenças são expressas em frases que incentivam a crença no trabalho cooperativado entre as pessoas, que enfatizam que o conhecimento e o crescimento das pessoas é que promovem o desenvolvimento da empresa, entre outros. Veja-se, na tabela 2, os resultados da análise descritiva das variáveis indicadas.

Tabela 2 - Variáveis de filosofia e valores

\begin{tabular}{llccc}
\hline Dimensões & Itens & Média & DP & $\begin{array}{c}\text { \% } \\
\text { Conc. }\end{array}$ \\
\hline Valores essenciais para a & - valoriza trabalhos em grupo & 4,02 & 1,241 & $65,70 \%$ \\
organização & - importância para os resultados das & 3,61 & 1,280 & $64,10 \%$ \\
& pessoas & & & \\
& - grande preocupação com as pessoas & 3,50 & 1,369 & $54,70 \%$ \\
& - muita importância para o desempenho & 4,11 &, 961 & $78,20 \%$ \\
& empresarial & & & \\
& - decisões consideram o impacto nas & 3,72 & 1,015 & $67,20 \%$ \\
& pessoas & & & \\
\hline Comunicação interna & - senso de responsabilidade coletiva & 3,53 & 1,447 & $50,00 \%$ \\
& - atitudes e comportamentos na empresa & 4,77 & 1,020 & $86,00 \%$ \\
& - acesso às informações e aos resultados & 3,75 & 1,425 & $64,10 \%$ \\
& - práticas condizentes com valores & 3,98 & 1,241 & $67,20 \%$ \\
& - regras explícitas & 3,88 & 1,062 & $67,20 \%$ \\
& - clareza nos resultados esperados & 3,34 & 1,405 & $43,80 \%$ \\
& - clareza dos propósitos da empresa & 3,77 & 1,065 & $59,30 \%$ \\
\hline
\end{tabular}

Fonte: elaborada pelos autores.

4) escala de seis pontos, sendo: 1 = discordo totalmente; 6 = concordo totalmente; ii) $\%$ concordo $=$ somatória de 6 (concordo totalmente) +5 (concordo muito) +4 (concordo pouco); iii) $\mathrm{DP}=$ desvio-padrão.

Os resultados demonstram que a prática de participação nas discussões das normas e regras administrativas (flexibilização das normas) atinge os objetivos da internalização das atitudes e dos comportamentos aceitos pela organização, pois são legitimados pelo grupo (mais alta média do bloco de questões). O desempenho organizacional é de alta relevância (controlado pela governança cooperativada), mas os dados indicam que os colaboradores não têm plena clareza sobre quais resultados a empresa espera de cada um.

A internalização da filosofia e dos valores demonstrou ser significativa, com ênfase nos seguintes aspectos: i) intensa promoção do diálogo sobre as questões que caracterizam o dia a dia da empresa, encorajando o surgimento de ideias em todos os níveis da organização; ii) crescente valorização do tema inovação como elemento estratégico, mesmo como "tema novo/ prática antiga" na empresa; iii) valorização dos trabalhos em grupo, além dos Comitês de Carne e de Leite (equipes de Pesquisa e Desenvolvimento). A história da empresa, proveniente da união de forças de produtores rurais, transmite que simplicidade não é sinônimo de acanhamento nos negócios. Ao acreditarem no potencial da região, transmitem confiança nas próprias ideias, ousadia, empenho e competência de gestão ao concretizá-las, obtendo sucesso contínuo nos seus resultados. O seu propósito essencial de "conquistar o consumidor oferecendo soluções em alimentação" expressa uma amplitude de concepção que pode ir além das soluções atualmente desenvolvidas. Esses são valores transmitidos aos colaboradores da Frimesa (embora não explicitamente), quando se mantêm os comitês de discussão sobre o dia a dia da 
empresa sem receio do debate ou do enfrentamento das ideias (COLLINS; PORRAS, 1996, apud ULRICH, 2000).

\subsubsection{Políticas e sistemas de recursos humanos}

A área de $\mathrm{RH}$, na empresa, está diretamente ligada à Diretoria Executiva da matriz e atende a todas as filiais com diretrizes estratégicas, táticas e operacionais. Nas filiais, há um profissional específico para atender às demandas locais e atuar na interface com a matriz:

a) seleção e contratação: a partir de 2004, a empresa ampliou 21,44\% do seu quadro de colaboradores, atingindo 2.889 funcionários diretos e apresentou um percentual de aumento nas contratações de $46,04 \%$. As demissões foram de 12,03\%, com índice de rotatividade geral em média $-0,49 \%$;

b) treinamento e desenvolvimento: os programas de capacitação leiteira e suinícula são realizados por assistência técnica, que assessora no manejo, no controle e na formulação da alimentação dos animais, na adequação das instalações e no controle sanitário. Pelos demais programas, percebe-se que a mentalidade em torno da criatividade voltada para a solução de problemas é também instigada nas atividades produtivas. Por exemplo, a empresa oferece palestras e cursos aos colaboradores com temas que abordam a relevância da criatividade para a inovação, a aprendizagem ativa, a gestão colaborativa, a liderança compartilhada, entre outros. No nível das lideranças, há o programa de "Formação de Liderança Organizacional", que oferece cursos com profissionais externos convidados para ministrar cursos e palestras sobre temas como habilidade de liderança, administração de conflitos, foco no resultado e outros;

c) avaliação de desempenho: a avaliação é informal e não é relacionada à remuneração. Os gestores são estimulados para a gestão de pessoas, conforme perfil e pré-requisitos dos cargos associados à sua liderança. Conforme uma das entrevistadas, já estava em andamento um projeto-piloto na área da Qualidade para Avaliação 360우

d) carreiras e promoção: para a promoção e as transferências, a empresa emprega a política de recrutamento interno, e, desde 2004, foram alçados, para cargos mais elevados na empresa, 3,03\% do total dos funcionários. No nível de supervisão, a promoção se dá por decisão da Diretoria;

e) remuneração e incentivos: além dos previstos pela legislação, são inúmeros os incentivos que a empresa oferece a todos os colaboradores de todas as unidades fabris, que atendem às demandas de alimentação, saúde, formação, lazer, entre outros. Não há sistema de benefícios e incentivos específicos para o pessoal locado em P\&D e gerador das inovações. Para os funcionários com têm ideias que geram retorno para a empresa, há aumentos salariais (sete casos até o momento das entrevistas, e a maioria do chão de fábrica), premiação com viagens, destaque com reportagem na revista da empresa. Um dos casos de promoção por ideia que gerou resultados para a empresa foi o de uma embalagem bem sucedida: o funcionário era assistente técnico e passou a ocupar a função de supervisor de desenvolvimento de embalagens. A tabela 3 apresenta os resultados da análise descritiva dessas variáveis. 
Tabela 3 - Variáveis de políticas e sistemas de recursos humanos

\begin{tabular}{llccc}
\hline Dimensões & Itens & Média & DP & $\%$ Conc. \\
\hline Seleção/contratação & - contrata visando à carreira & 3,53 & 1,368 & $51,60 \%$ \\
& - seleção é rigorosa & 3,16 & 1,525 & $45,30 \%$ \\
\hline Treinamento e & - treinamentos para novas funções & 3,81 & 1,271 & $65,60 \%$ \\
desenvolvimento & - pessoas capacitadas mais funções & 3,69 & 1,067 & $61,00 \%$ \\
& - investe no treinamento de pessoal & 3,94 & 1,320 & $64,10 \%$ \\
\hline Avaliação de desempenho & - discutem melhorias no desempenho & 3,28 & 1,397 & $46,90 \%$ \\
& - metas definidas em conjunto & 3,11 & 1,223 & $40,70 \%$ \\
& - desempenho colaboradores hoje & 3,69 & 1,125 & $59,30 \%$ \\
\hline Carreira & - seguir carreira na empresa & 3,89 & 1,427 & $64,10 \%$ \\
& - cargos vagos com pessoas internas & 4,30 & 1,364 & $76,10 \%$ \\
\hline Incentivos & - incentivo a ideias inovadoras & 3,08 & 1,186 & $37,50 \%$ \\
& - incentivos vinculados aos resultados & 2,81 & 1,446 & $34,90 \%$ \\
& - incentivo a resultados coletivos & 3,61 & 1,163 & $59,40 \%$ \\
\hline Remuneração & - salário na carreira e desempenho & 2,81 & 1,446 & $34,90 \%$ \\
& - salários compatíveis ao desempenho & 2,59 & 1,294 & $26,60 \%$ \\
\hline
\end{tabular}

Fonte: elaborada pelos autores.

i) escala de seis pontos, sendo: $1=$ discordo totalmente; 6 = concordo totalmente;

ii) \% concordo = somatória de 6 (concordo totalmente) +5 (concordo muito) +4 (concordo pouco);

iii) $\mathrm{DP}=$ desvio-padrão.

A possibilidade de seguir carreira associada às oportunidades de desenvolvimento profissional na organização foi o item mais evidenciado pelos colaboradores nas variáveis de políticas e sistemas de recursos humanos. A prática de seleção interna, nas oportunidades de promoção, com treinamentos continuados, reforça a crença da organização na capacidade de seus colaboradores. As práticas de remuneração associadas ao desempenho e à carreira obtiveram as menores médias, moderadamente compensadas pelos incentivos praticados pela organização. Já os incentivos à inovação são os menos praticados.

Enquanto a estratégia voltada à inovação tecnológica é enfatizada na pesquisa e no desenvolvimento de produtos, a Frimesa prepara seu corpo de líderes e colaboradores para germinar a inovação em todas as suas modalidades, em todos os níveis e em todas as áreas da organização, por intermédio de treinamentos que pratiquem os conteúdos de maneira transversal aos processos produtivos. O alinhamento estratégico entre inovação e gestão de pessoas evidencia-se como construção de cultura, favorecendo a aprendizagem individual e coletiva na organização (LEEDE; LOOISE, 2005; ALBUQUERQUE, 1999; 2002).

\subsection{Apresentação das variáveis de espaço para a criatividade}

Uma simples adaptação no sistema de higienização automatizada em uma unidade de lácteos, transformando-a toda em circuito fechado, gerou economia de 32\% no volume da limpeza. O projeto abrangeu a equipe de manutenção eletroeletrônica, que adaptou os equipamentos em toda a fábrica com dosadores de produtos de limpeza, juntamente com a instalação de mini-centrais diluidoras das soluções químicas, atendendo ao compromisso da empresa com o meio ambiente. A ideia executada foi amplamente discutida com todos os setores pertinentes, pois, segundo um dos entrevistados, "as melhores ideias são aquelas postas em discussão". É dessa maneira que a empresa, até então, menos preocupada em gerar inovações e, mais 
ainda, em colher resultados efetivos com as ideias sugeridas, estimula a criatividade entre seus colaboradores.

Os itens a seguir apresentam os resultados da análise descritiva referentes à percepção dos colaboradores técnicos e administrativos sobre as variáveis de espaço para a criatividade.

\subsubsection{Encorajamento para a criatividade}

Os resultados das variáveis referentes estão contidos na tabela 4.

Tabela 4 - Variáveis de encorajamento para a criatividade

\begin{tabular}{llccc}
\hline Dimensões & Itens & Média & DP & \% Conc. \\
\hline Receptividade pela organização & - organização receptiva às ideias & 4,36 &, 966 & $78,10 \%$ \\
\hline Incentivos dos gestores e colegas & - confiança nos colegas e no(s) & 4,03 & 1,356 & $68,30 \%$ \\
& gestor(es) & & & \\
& - gestor(es) encoraja(m) & 4,05 & 1,327 & $56,30 \%$ \\
& - à vontade para expor ideias & 4,05 & 1,250 & $69,80 \%$ \\
& - estimulado(a) a enfrentar desafios & 3,84 & 1,224 & $57,80 \%$ \\
& - níveis mais altos acreditam na & 3,86 & 1,153 & $62,50 \%$ \\
& capacidade criativa & & & \\
\hline Espontaneidade e fluência das & - à vontade para agir diferente & 3,89 & 1,175 & $71,00 \%$ \\
ideias & - trabalham bem em equipe & 4,67 & 1,085 & $86,00 \%$ \\
& - ideias criativas com frequência & 3,88 &, 826 & $72,40 \%$ \\
\hline Tolerância ao erro e feedbacks & - gestor(es) tolera(m) erros & 3,73 &, 902 & $60,40 \%$ \\
construtivos & - gestor(es) feedbacks construtivos & 3,38 & 1,431 & $51,60 \%$ \\
& - gestor(es) considera(m) "erros"como & 3,61 &, 986 & $51,70 \%$ \\
\hline Incentivo à ampla comunicação & aprendizagem & & & \\
entre as áreas & grupos & 3,73 & 1,185 & $67,20 \%$ \\
\hline
\end{tabular}

Fonte: elaborada pelos autores.

i) escala de seis pontos, sendo: $1=$ discordo totalmente; 6 = concordo totalmente;

ii) $\%$ concordo = somatória de 6 (concordo totalmente) +5 (concordo muito) +4 (concordo pouco);

iii) $\mathrm{DP}=$ desvio-padrão.

O desenvolvimento do trabalho em grupos é favorecido pelo clima de receptividade das ideias e de reciprocidade pelos colegas e pela organização. Esse clima é alimentado na empresa através da participação e do diálogo em grupos ("local" criativo) em que os gestores encorajam os colaboradores a exporem suas ideias, a experimentarem novas formas de executar o trabalho e a enfrentar os desafios e encontrar soluções inovadoras para os problemas. Essas práticas levam os colaboradores a sentir-se mais valorizados na sua capacidade criativa pelas pessoas que compõem os níveis mais altos da hierarquia, e é provável que essa crença favoreça a renovação das ideias com maior frequência. Além disso, os diálogos em grupos estão intimamente ligados à qualidade da comunicação interna e do ambiente colaborativo, além de favorecer a espontaneidade e a criticidade necessárias à fluência das ideias (ALBUQUERQUE, 1999; AMABILE et al., 1996).

As menores médias referem-se ao feedback construtivo e à aprendizagem com o "erro" proveniente do exercício criativo. Ressalta-se que as variáveis de encorajamento à criatividade apresentaram os menores desvios-padrão de todo o caso. 
A intenção estratégica de introduzir o tema "inovação" no todo da organização, desdobrado em temas de cursos e capacitações ao conjunto dos seus líderes, é um importante passo para transcender a concepção da inovação restrita à Pesquisa e ao Desenvolvimento (P\&D). As condições para um continuum das ideias dos colaboradores, prática altamente estimulada e valorizada na organização, requerem aprimoramento nas técnicas de feedback construtivo e maior valorização da aprendizagem com os "erros" provenientes do exercício criativo.

\subsubsection{Ambiente de tarefa}

A seguir, apresentam-se os resultados da análise descritiva referentes às variáveis apontadas.

Tabela 5 - Variáveis de ambiente de tarefa

\begin{tabular}{llccc}
\hline Dimensões & Itens & Média & DP & \% Conc. \\
\hline Autonomia e liberdade & - ser mais criativo(a) e imaginativo(a) & 4,85 &, 973 & $91,90 \%$ \\
& - diretrizes claras pensar e decidir & 3,77 &, 988 & $61,00 \%$ \\
& - liberdade para decidir sobre tarefas & 4,41 &, 868 & $84,40 \%$ \\
& - incentivo a pensar e decidir & 3,91 &, 971 & $75,00 \%$ \\
\hline Pressão no ambiente & - sobrecarregado(a) de trabalho & 3,91 & 1,165 & $62,50 \%$ \\
de trabalho & - escassez de tempo & 4,03 & 1,154 & $65,60 \%$ \\
& - pressão pela produtividade & 3,97 & 1,140 & $70,40 \%$ \\
\hline
\end{tabular}

Fonte: elaborada pelos autores.

i) escala de seis pontos, sendo: 1 = discordo totalmente; 6 = concordo totalmente;

ii) \% concordo = somatória de 6 (concordo totalmente) +5 (concordo muito) +4 (concordo pouco);

iii) DP = desvio-padrão;

Os resultados apresentam relativa pressão pela produtividade e desempenho com valorização da autonomia e da liberdade, elementos relevantes para a construção do espaço para a criatividade, pois propiciam o aspecto desafiador e o crescimento intelectual, à medida que estejam alicerçadas no intento estratégico da organização (EKVALL, 1996; ISAKEN et al., 20002001; KWASNIESWSKA; NECKA, 2004; ALBUQUERQUE, 1999; 2002). Ressalta-se que o estímulo de participação nas discussões que a organização oferece aos seus colaboradores instiga o exercício convergente/divergente do pensamento criador.

A maior média, no estudo de caso, refere-se ao anseio dos colaboradores por oportunidades de criatividade na realização de suas tarefas (maior média de todo o estudo de caso), instigados pela constância da participação e do diálogo promovidos pela empresa e pelas capacitações realizadas (e em desenvolvimento) voltadas ao tema. 


\subsubsection{Recursos}

A tabela 6 apresenta os resultados da análise descritiva referentes às variáveis observadas.

Tabela 6 - Variáveis de recursos

\begin{tabular}{llccc}
\hline Dimensões & Itens & Média & DP & \% Conc. \\
\hline Recursos financeiros & - não recursos para novas ideias & 3,36 & 1,302 & $49,90 \%$ \\
Tempo & - respeito ao tempo da ideia & 3,92 & 1,997 & $68,70 \%$ \\
Recursos materiais & - recursos materiais disponíveis & 4,31 & 1,355 & $73,50 \%$ \\
Ambiente físico & - agradável e saudável & 4,42 & 1,257 & $76,50 \%$ \\
Recursos tecnológicos & - recursos tecnológicos disponíveis & 4,08 & 1,238 & $76,50 \%$ \\
\hline
\end{tabular}

i) escala de seis pontos, sendo: $1=$ discordo totalmente; 6 = concordo totalmente;

ii) \% concordo = somatória de 6 (concordo totalmente) +5 (concordo muito) +4 (concordo pouco);

iii) DP = desvio-padrão.

A agradabilidade do ambiente físico é destacada pelos colaboradores, possivelmente pelas novas instalações que, tanto em Curitiba quanto em Medianeira, são contempladas por amplas áreas verdes e amplas instalações e constituem recursos considerados fundamentais para a fluência da criatividade (AMABILE et al., 1996). Dentre os recursos, os materiais, seguidos pelos tecnológicos, são os mais disponibilizados, provavelmente em função das inovações em processo na empresa com a introdução de novas tecnologias. Os recursos para novas ideias revelaram a menor média do bloco de questões, provavelmente em função de os maiores investimentos serem destinados aos Comitês de Carne e de Leite. Os investimentos também são destinados aos processos produtivos inovadores.

\subsubsection{Impedimentos organizacionais}

A seguir, os resultados dos impedimentos organizacionais.

Tabela 7 - Variáveis de impedimentos organizacionais

\begin{tabular}{llccc}
\hline Dimensões & Itens & Média & DP & \% Conc. \\
\hline Criticidade/espontaneidade & - pessoas criativas são muito críticas & 4,14 & 1,148 & $71,40 \%$ \\
& - espontaneidade incompatível & 3,38 & 1,275 & $46,10 \%$ \\
\hline Mudanças organizacionais & - mudança encontra resistência & 3,35 & 1,259 & $42,80 \%$ \\
& - receio de perder espaço ou emprego & 3,95 & 1,156 & $68,20 \%$ \\
\hline Influências sociais, políticas e & - tradições e regras dificultam inovações & 3,56 & 1,067 & $53,20 \%$ \\
administrativas & - problemas políticos na comunicação & 3,67 & 1,437 & $53,10 \%$ \\
& - motivos políticos rejeitam projetos & 3,50 & 1,222 & $53,20 \%$ \\
\hline Inter-relacionamento com colegas & - muita rivalidade na equipe & 2,75 & 1,436 & $26,60 \%$ \\
\hline
\end{tabular}

Fonte: elaborada pelos autores.

i) escala de seis pontos, sendo: 1 = discordo totalmente; 6 = concordo totalmente;

ii) \% concordo = somatória de 6 (concordo totalmente) +5 (concordo muito) +4 (concordo pouco);

iii) $\mathrm{DP}=$ desvio-padrão. 
Os resultados de impedimentos organizacionais revelam certo receio dos colaboradores na manutenção do emprego com o advento das mudanças e da introdução de inovações. Os problemas políticos afetam moderadamente a comunicação interna, provavelmente em função do sistema de gestão por governança cooperativada. Ressalta-se o baixo nível de rivalidade nas equipes de trabalho, reforçado pelos resultados da tabela 5, na qual os colaboradores apontam que trabalham bem em equipes e, na tabela 4, em que os incentivos aos resultados coletivos são os mais considerados. Evidencia-se, portanto, que o trabalho desenvolvido em grupo é um dos valores essenciais para a organização.

As tradições e normas vigentes são neutralizadas pelas discussões sobre a validade das mesmas no dia a dia da empresa, e a criticidade e a espontaneidade também não foram consideradas impedimentos ao espaço para a criatividade na organização. Os problemas políticos afetam moderadamente a comunicação interna, provavelmente pelo sistema de gestão por governança cooperativada.

\section{CONCLUSÃO}

Para contribuir com as discussões propostas pelo artigo, destaca-se que, dentre as estratégias nas organizações inovativas, o caso apresentado evidenciou as políticas e práticas de gestão de pessoas que propiciam evidenciar a criatividade como uma importante alavanca da inovação na empresa (SBRAGIA et al., 2006).

Apesar das limitações que um estudo de caso oferece, ou seja, a impossibilidade de generalizar os resultados e responder aos "porquês" que determinam uma relação de causa e efeito, a pesquisa apresenta algumas contribuições relevantes. Entre elas, destacam-se as evidências de que a gestão estratégica de pessoas para a inovação deve estender-se aos colaboradores de todas as áreas e não somente àqueles locados em P\&D. Todos os colaboradores, inclusive os participantes das atividades inovativas, concorrem para o cumprimento do intento estratégico da organização.

Verificou-se que os resultados da pesquisa convergem para as tendências de gestão de pessoas, incorporadas à tentativa de alcançar as capacidades integrativas para a consecução da estratégia organizacional de obtenção de resultados com inovação. As características organizacionais evidenciadas no estudo do caso apontam que: i) a estrutura organizacional hierarquizada é neutralizada com a intensificação da participação dos funcionários nas discussões de ideias com potencial de inovação e na flexibilização de normas e regras; ii) em filosofia e valores, percebeu-se a valorização do trabalho organizado em grupos, intensa promoção do diálogo sobre as questões do dia a dia da empresa, a agregação das habilidades de vários indivíduos, maior diversidade de opiniões (favoráveis ao pensamento divergente) e maior aceitação de decisões tomadas coletivamente (ALBUQUERQUE, 2002; DUTRA, 2002; ROBBINS, 2005; LEEDE; LOOISE, 2005; MARTIN-ALCAZAR; ROMERO-FERNANDEZ; SANCHEZ-GARDEY, 2005). São dimensões que rearfirmam o encorajamento à criatividade no ambiente organizacional (aspectos da abordagem sociointeracionista da criatividade), traduzido nos expressivos resultados alcançados nas dimensões "autonomia e liberdade". E, para concluir: iii) as políticas e práticas de gestão de pessoas mais evidenciadas são as relacionadas à prática de seleção interna nas oportunidades de promoção e os intensos treinamentos, voltados ao corpo de colaboradores em geral, com o objetivo de construir uma cultura de inovação na empresa.

Percebeu-se ainda que, na empresa estudada, a integração entre as estratégias de gestão de pessoas contribui fortemente para os resultados com inovação, com forte ênfase na 
participação dos colaboradores em geral, como valor essencial à organização, e que as atividades inovativas atuam como suporte para essa dinâmica intraorganizacional. Infere-se que essa particularidade possa ser característica do setor de laticínios, de baixa densidade tecnológica e com contínua inserção de novos produtos no mercado.

As contribuições para as instituições de ensino e pesquisa se voltam para as discussões teóricas e práticas sobre a gestão estratégica das pessoas e, na área da gestão da inovação, para a compreensão da criatividade como uma das alavancas para a inovação, dados os escassos estudos disponíveis. Para os processos de gestão, as organizações interessadas em obter resultados com inovação podem utilizar esta pesquisa como referencial, viabilizando o encorajamento e a valorização de seus colaboradores pelos resultados dela proveniente.

Como sugestões de tema para futuras pesquisas, o estudo de caso demonstrou que o alinhamento estratégico entre inovação e gestão de pessoas envolve competências gerenciais voltadas para sua sustentação. Sugere-se, assim, verificar as competências gerenciais para esse alinhamento, que considerem os níveis diferenciados de consciência em que os gestores apreendem, atuam e comunicam o intento estratégico da organização.

\section{REFERENCIAS BIBLIOGRÁFICAS}

ALBUQUERQUE, L. G. Estratégica de recursos humanos e competitividade. In: VIEIRA, M. M. F.; OLIVEIRA, L. M. B. (Org.). Administração contemporânea: perspectivas estratégicas. São Paulo: Atlas, 1999. p. 215-238.

A gestão estratégica de pessoas. In: FLEURY, M. T. L. (Org.). As pessoas na organização. São Paulo: Gente, 2002. p. 35-50.

ALIAGA, O. A. A study of innovative human resource development practices in Minnesota companies. 2005. Tese (Doutorado em Psicologia)Faculty of The Graduate School of the University of Minnesota, Local?, 2005. Disponível em: < http:// richardswanson.com/hrdrcreports/Aliaga2005innovation>. Acesso em: 25. jan. 2007.

AMABILE, T. M. How to kill creativity. Harvard Business Review, Boston, v. 76, n. 5, p. 76-87, Sept./Oct. 1998.

AMABILE, T. M. et al. Assessing the work environment for creativity. Academy of Management Journal, v. 39, n. 5, p. 1154-1184, Oct. 1996.

AMABILE, T. M.; GRYKIEWICZ, N. D. The creative environment scales: work environment inventory. Creativity Research Journal, v. 2, p. 231-253, 1989.
AMO, B. W.; KOLVAREID, L. Organizational Strategy, Individual Personality and Innovation Behaviour. Journal of Enterprising Culture, v 13, n. 1, p 7-19, Mar. 2005.

CHANG JR. Gestão de pessoas pelo desenvolvimento do comprometimento organizacional: uma abordagem holística e simultânea dos determinantes envolvidos no processo. 2001. Tese (Doutorado em Administração)-Faculdade de Economia e Administração, Universidade de São Paulo, São Paulo, 2001.

COLLINS, J. C; PORRAS, J. I. Construindo a visão de sua empresa. In ULRICH, D. (Org.). Recursos humanos estratégicos. Tradução Cristina Bazán, Bazán Tecnologia e Lingüística. São Paulo: Futura, 2000.

DUTRA, J. S. Gestão de pessoas: modelo, processos, tendências e perspectivas. São Paulo: Atlas, 2002.

EKVALL, G. Organizational climate for creativity and innovation. European Journal of Work and Organizational Psychology, v. 5, n 1, p. 105-123, 1996.

FERRIS, G. et al. Human Resources Management: Some New Directions. Journal of Management, $v$. 25, n. 3, p. 385-415, 1999. 
FINEP. Financiadora De Estudos E Projetos. Manual de Oslo. 3. ed. Ministério da Ciência e Tecnologia, Rio de Janeiro: 2005. Disponível em: <http:// www.finep.gov.br>. Acesso em: 20 jun. 2007.

FURTADO, A. T.; CARVALHO, R. Q. Padrões de intensidade tecnológica da indústria brasileira: um estudo comparativo com os países centrais. Revista São Paulo em Perspectiva, v. 19, n. 1, p. 70-84, jan./ mar. 2005.

HIPÓLITO, J. A. M. Administração salarial: a remuneração por competências como diferencial competitivo. São Paulo: Atlas, 2001.

IPEA. Instituto de Pesquisa Econômica Aplicada. Brasil: o estado de uma nação. IPEA: 2006. Disponível em: <http://www.ipea.org.br>. Acesso em: 25. jul. 2006.

IBGE. Instituto Brasileiro de Geografia e Estatística. Pesquisa Industrial de Inovação Tecnológica/ PINTEC. IBGE: 2003. Disponível em: <http:// www.ibge.gov.br>. Acesso em: 1 dez. 2006.

Pesquisa de Inovação Tecnológica/ PINTEC. IBGE: 2008. Disponível em: <http:// www.ibge.gov.br>. Acesso em: 1 dez. 2010.

ISAKEN, S. G. et al. Perceptions of the best and worst climates for creativity: preliminary validation evidence for the Situational Outlook Questionnaire. Creativity Research Journal, v. 13, n. 2, p. 171 184, 2000-2001.

JONASH, R. S. O valor da inovação: como as empresas mais avançadas atingem alto desempenho e lucratividade. Rio de Janeiro: Campus, 2001.

KWASNIEWSKA, J.; NECKA, E. Perception of climate for creativity in the workplace: the role of the level in the organization and gender. Creativity and Innovation Management, v. 13, n. 3, p. 187-196, Sept. 2004.

LAURSEN, K.; FOSS, N. J. New human resource management oractices, complementarities and the impact on innovation performance. Cambridge Journal of Economics, v. 27, p. 243-263, 2003.

LEEDE, J. De; LOOISE, J. K. Innovation and HRM: towards an integrated framework. Creativity and Innovation Management, v. 14, n. 2, p. 108-117, 2005.
MARTIN-ALCAZAR, F.; ROMERO-FERNANDEZ, P.; SANCHEZ-GARDEY. Strategic human resource management: integrating the universalistic, contingent, configurational and contextual perspectives. International Journal of Human Resource Management, v. 16, n. 5, p. 633-659, May 2005.

PAROLIN, S. R. H.; ALBUQUERQUE, L. G. Gestão de pessoas para a criatividade em organizações inovativas. Revista Eletrônica de Administração, Edição 67, v. 16, n. 3, p. 268-297, set./dez. 2010.

PAROLIN, S. R. H. Características organizacionais e espaço para a criatividade em organizações inovativas. 2008. 226f. Tese (Doutorado em Administração)- Universidade de São Paulo, São Paulo, 2008.

POHLMANN, M.; GEBHARDT, C.; ETZKOWITZ, H. The Development of Innovation System and the Art of Innovation Management - Strategy, Control and the Culture of Innovation. Technology Analysis \& Strategic Management, v. 17, n. 1, p 1-7, Mar. 2005,

ROBBINS, S. P. Administração: mudanças e perspectivas. Tradução Cid Knipel Moreira. São Paulo: Saraiva, 2005.

ROESCH, S. M. A. Projetos de estágio e de pesquisa em administração. 2. ed. São Paulo: Atlas, 1999.

SBRAGIA, R. (Coord.) et al. Inovação: como vencer esse desafio empresarial. São Paulo: Clio, 2006.

SIMANTOB, M.; LIPPI, R. Guia valor econômico de inovação nas empresas. São Paulo: Globo, 2003.

SLUIS, L. E. C. Van der. Desinging the workplace for learning and innovation. Development and learning organizations, v. 18, n. 5, p. 10-13, 2004

SWAN, F.; SUE, N.; SCARBROUGH, H.; HISLPO, D. Knowledge management and innovation: networks and networking. Journal of Knowledge management, v.3, n.4, p. 262-275, 1999.

ULRICH, D. Recursos humanos estratégicos. In: (Org.). Tecnologia e lingüística. Tradução Cristina Bazán, Bazán. São Paulo: Futura, 2000.

VASCONCELLOS, E.; HEMSLEY, J. Estrutura das organizações: estruturas tradicionais, estruturas para inovação, estrutura matricial. São Paulo: Pioneira Thomson Learning, 2003. 